\title{
O ENCONTRO ENTRE PEDAGOGIA FREIRIANA E PEDAGOGIA FEMINISTA
}

\author{
The meeting between Freirian Pedagogy and \\ Feminist Pedagogy
}

Paula Vielmo ${ }^{1}$

\begin{abstract}
Resumo: A pedagogia freiriana se encontra com a pedagogia feminista. E, mais do que um encontro, é inspiração para que as feministas desenvolvam uma pedagogia própria que trate acerca das opressões vividas pelas mulheres em suas dimensões de gênero, raça, classe e sexualidade, buscando por meio de uma práxis feminista, transformar a sociedade patriarcal capitalista de supremacia branca. Este texto objetiva refletir sobre o encontro entre Pedagogia Freiriana e Pedagogia Feminista e as possibilidades transformadoras que se abrem a partir dele. É um ensaio teórico que convida quem adere a pedagogia do oprimido a igualmente aderir a uma pedagogia que veja o oprimido como além de um homem, exercitando assim a criação para a qual Paulo Freire nos chamou a fazer a cada uma de suas obras, chamado alinhado com a proposta feminista de transformação da sociedade.

Palavras-chave: Paulo Freire. Pedagogia Freiriana. Pedagogia Feminista.
\end{abstract}

Abstract: Freirian pedagogy meets feminist pedagogy. And more than an encounter, it is inspiration for feminists to develop their own pedagogy that deals with the oppressions experienced by women in their gender, race, class and sexuality dimensions, seeking through a feminist praxis, transform the capitalist patriarchal society of white supremacy. This text objective to reflect on the meeting between Freiriana Pedagogy and Feminist Pedagogy and the transformative possibilities that open up from it. It is a theoretical essay that invites those who adhere to the pedagogy of the oppressed to also adhere to a pedagogy that sees the oppressed as beyond a man, thus exercising the creation for which Paulo Freire called us to make to each of his works, called aligned with the feminist proposal of transformation of society.

Keywords: Paulo Freire. Freirian Pedagogy. Feminist Pedagogy.

\footnotetext{
${ }^{1}$ Mestranda em Estudos Interdisciplinares sobre mulheres, gênero e feminismo (UFBA). Especialista em Educação em Gênero e Direitos Humanos (NEIM/ UFBA). Graduada em Licenciatura em Pedagogia (UNEB). Pedagoga no IFBA Campus Barreiras. Orcid: https://orcid.org/0000-0002-3743-4801
} 


\section{Introdução ou primeiras palavras}

(...) Se alguma das ideias aqui apontadas lembram as propostas de Paulo Freire, isso também não é uma coincidência.

Gracira Lopes Louro (2011, p. 119)

O centenário do aniversário de Paulo Freire (1921-2021), patrono da educação brasileira, motivou a realização de inúmeras homenagens. Esse reconhecimento ocorreu em diversas partes do mundo por meio de cursos, eventos e chamadas para publicações que evidenciam as contribuições de Paulo Freire. A vivacidade do legado freiriano estimula a refletir acerca de nosso tempo, nossos desafios e da criação de inéditos viáveis diante de tantas situações-limites em um período de crise do capital e da reprodução social (FEDERICI, 2021), associada a uma crise sanitária pela pandemia de Covid-19.

Nesse caminho, este trabalho é também uma homenagem que busca trazer para o centro dos diálogos educativos temas ainda presentes de modo insuficiente, mesmo que componham as relações sociais. Refiro-me às relações de gênero, raça, sexualidade e de classe, mais precisamente por meio da pedagogia feminista associada à pedagogia freiriana. Assim, este texto prossegue reflexões iniciadas em uma primeira publicação (VIELMO, 2020) e na exposição realizada durante o curso de extensão Ciclos Freirianos $(\mathrm{UnB})^{\mathrm{i}}$, cujo tema foi Gênero e Pedagogia Feminista na Educação como prática da Liberdade. Para tanto, objetiva refletir sobre o encontro entre Pedagogia Freiriana e Pedagogia Feminista e as possibilidades transformadoras que se abrem a partir dele. Faço isso por meio de uma revisão bibliográfica associada à experiência como pedagoga feminista.

Já neste aspecto, percebo relações entre a produção freiriana e a produção feminista, pois ambas partem da realidade do sujeito para ampliar sua visão de mundo ou partir do saber de "experiência feito" (FREIRE, 1996, p. 103) a ser superada por meio de uma condução que desloque para o saber científico. No caso do movimento feminista, partir das experiências das mulheres, equivale a levar a percepção como sujeito de um grupo social, perceber que as violências e obstáculos são produzidos pelas relações desiguais de gênero e raça numa sociedade pautada pela exploração, já que as mulheres são um grupo atravessado por outras opressões além da do gênero.

Entendo gênero como a historiadora estadunidense Joan Scott (1995), que apresentou gênero como categoria de análise histórica, considerando-o como um elemento que compõe todas as relações sociais, baseando-se nas diferenças aparentes entre os sexos e um modo elementar de dar significado às relações de poder. Ao falar em poder, implica dizer que falamos em hierarquia e assimetria; entre opressores e oprimidas, dominadores e dominadas. Nessas relações envolvendo mulheres e homens, os homens são em geral os principais opressores, mas há também opressão intragênero.

Como o foco da pedagogia feminista são as mulheres, um exemplo evidente destas relações de poder intragênero no Brasil é a entre mulheres com ensino superior e

Rev. Nova Paideia - Revista Interdisciplinar em Educação e Pesquisa Brasília/DF, v. 3, n. 3. p. 36 - 48 - ANO 2021 
melhores postos de trabalho, em geral brancas, que utilizam do trabalho doméstico de mulheres com baixa escolaridade e oriundas de famílias pobres, em geral negras, cuja remuneração é muito baixa.

\begin{abstract}
Essa afirmação soaria coloquial não apenas em função da banalização que se faz da presença das mulheres no serviço doméstico, mas também pelo racismo estrutural que, em alguma medida, aprisiona os corpos de mulheres negras nas mesmas atividades realizadas na cozinha da casa grande durante o período de escravização. (PINHEIRO et al, 2019, p. 11)
\end{abstract}

São mais de 5,7 milhões de mulheres como trabalhadoras domésticas, a maior categoria feminina (PINHEIRO et al, 2019). Apesar de ser um tema presente na agenda feminista, permanece à margem. Sobre isso, bell hooks ii (2019) colabora com a reflexão ao destacar às feministas o quanto é fundamental dar atenção aos trabalhos subalternos, pois lá estará a massa de mulheres trabalhadoras, afinal:

acabar com a exploração econômica das mulheres poderia se tornar o ponto da agenda feminista que atenderia ao interesse da massa das mulheres, demolindo com isso as barreiras que separam o pequeno grupo de mulheres que participam ativamente das organizações feministas daquela grande maioria de mulheres que estão fora destas organizações. (hooks, 2019, p. 154)

A autora associa ainda a exploração sexista das mulheres ao grau de instrução das mesmas, chamando atenção para a educação das mulheres, desde a alfabetização, encorajando "as mulheres a luta por sua formação, a desenvolver seu intelecto", o que para bell hooks "deveria ser o objetivo primordial do movimento feminista" (hooks, 2019 , p. 173). Essas complexas relações de poder, desveladas ao longo dos tempos pelas teorias e movimentos feministas e que ainda estão em curso de produção e transformação social, contou com suporte fundamental do pensamento de Paulo Freire e sua educação como prática da Liberdade e pedagogia do oprimido.

Essa pedagogia se refez em pedagogia da oprimida e se expressou nos grupos de conscientização, reflexão e ação feministas (SARDENBERG, 2011), quando as mulheres ao se encontrarem para dialogar, percebiam as semelhanças da opressão e adentravam na conscientização, ajudando a si mesmas, o grupo social e os homens, principais opressores. Assim, a práxis reivindicada por Paulo Freire inspira a práxis feminista, afinal "(...) 0 feminismo é um modo de olhar o mundo que busca articular a análise das desigualdades de gênero, raça e classe no intuito de transformá-las, e que, por isso, exige coerência entre construção teórica e luta social para transformação" (SILVA, 2010, p. 1112). 


\section{Paulo Freire, mulheres, gênero e feminismo}

Retomando a importância da experiência para a pedagogia freiriana e a pedagogia feminista, considero relevante situar brevemente a leitora e o leitor do processo que me levou a tais reflexões, ou seja, situar minha relação com Paulo Freire, o movimento feminista e as teorias feministas.

O encontro com Paulo Freire ocorreu na Licenciatura em Pedagogia, cursada na Universidade do Estado da Bahia (UNEB) entre 2003 e 2008, no qual tive contato pequeno com o autor e nenhum com os estudos de gênero ou estudos feministas. Apesar de que, no início deste século XXI, já haviam décadas de existência do campo de estudos feministas no Brasil e da existência de núcleo de gênero e sexualidades na UNEB, nenhum desses debates ainda havia aportado no município do interior onde estava o Campus IX, em Barreiras.

O contato inicial com a obra freiriana ocorreu por meio de Pedagogia da Autonomia: saberes necessários à prática educativa (1996), tendo me chamado atenção para a escrita do autor de mulheres e homens, professoras e professores, educandas $e$ educandos, ou seja, pelo uso de ambos os gêneros. Até aquele momento, por volta de 2007, estava num curso feminizado, cursando pedagogia e agindo conforme as lições iniciais aprendidas na escola, tal qual afirma Guacira Lopes Louro:

É impossível esquecer que uma das primeiras e mais sólidas aprendizagens de uma menina na escola consiste em saber que, sempre que a professora disser que "os alunos que acabarem a tarefa pode ir para o recreio", ela deve se sentir incluída. Mas ela está sendo, efetivamente, incluída ou escondida nessa fala? Provavelmente é impossível avaliar todas as implicações dessa aprendizagem; mas é razoável afirmar que ela é, quase sempre, muito duradoura. (LOURO, 2011, p. 70)

Segundo monografia de Clea Gomes de Abreu dos Santos e Janaina de Oliveira de Alcantara (2021) que investigou a concepção de discentes do curso de Pedagogia no mesmo local em que me graduei, há fortes indícios da permanência de ausência de reflexões críticas envolvendo as relações de gênero na formação de pedagogas e pedagogos, mulheres que seguem se afirmando profissionais no masculino como expressão dessa sólida aprendizagem, mas sobretudo a ausência de consciência de gênero feminista (SARDENBERG, 2011).

Em alguma medida, em Pedagogia da Autonomia a mulher não estava mais escondida, mas lado a lado do homem. Paulo Freire deu visibilidade às mulheres em seus escritos devido à interpelação de feministas estadunidenses, que lhe escreviam perguntando sobre as mulheres em seus textos, problematizando a linguagem machista. Quanto a isso, ele inicialmente negou, mas logo refletiu que a negação tinha fundamento na ideologia patriarcal, tal como ele relata em Pedagogia da Esperança (2021). 
Devido a ter acesso a esta forma de escrita, adotei para a minha monografia à época, sobre $O$ movimento estudantil como espaço de formação política para o (a) pedagogo (a) (2008), uma escrita tal qual Freire, porém sem qualquer noção das relações de gênero, sem perceber a feminização da pedagogia ou como ocorria a participação de mulheres e homens no movimento estudantil. Isso me provoca reflexões sobre a visibilidade do sujeito, mas a invisibilidade das relações de gênero. Ao trazer mulheres e homens ao texto, não implicou em apreender as relações de poder, desigualdades e hierarquias criadas e recriadas pelo gênero.

Sem demora, por volta de 2009, me encontrei com o movimento e as teorias feministas, tendo acesso aos textos e publicações do Núcleo de Estudos Interdisciplinares sobre a Mulher (NEIM) da Universidade Federal da Bahia (UFBA) ${ }^{\text {iii. }}$. Destaco que ambas as publicações foram importantes apoios de formação feminista e abriram possibilidades para o que até então era desconhecido. Havia um artigo que me chamou atenção: Considerações introdutórias às pedagogias feministas, de autoria da antropóloga Cecília Sardenberg. Neste texto, a autora define pedagogia feminista como

conjunto de princípios e práticas que objetivam conscientizar indivíduos, tanto homens quanto mulheres, da ordem patriarcal vigente em nossa sociedade, dando-lhes instrumentos para superá-la e, assim, atuarem de modo a construir a equidade entre os sexos. (SARDENBERG, 2011, p. 19).

Apesar de perceber atualmente que a definição apresenta uma contradição com a afirmação feminista de que as pessoas se educam conjuntamente mediadas pela realidade concreta, à época e por muito anos guiou-me como educadora feminista no espaço escolar, na atuação sindical e partidária. Ademais, conforme afirmou Guacira Lopes Louro no trecho escolhido como epígrafe deste artigo, as ideias da pedagogia feminista lembram as ideias freirianas e não se trata de uma coincidência.

Suas críticas à "educação bancária" e sua proposta de uma "educação libertadora" são conhecidas internacionalmente e frequentemente são referências destacadas nas pedagogias feministas. É claro que, nesse caso, os sujeitos em foco são, primordialmente, as mulheres. (LOURO, 2011, p. 119)

0 foco nas mulheres implica em libertação de mulheres e homens, pois ao promover conscientização de uma parcela significativa da sociedade - as mulheres -, movimenta as relações de gênero em direção à transformação, cujas relações suprimam as desigualdades e violências, portanto o próprio gênero e a própria raça, que precisa ser considerada indispensável na análise, principalmente quando pensamos o Brasil.

\section{Diálogos promovem o ser mais}

Se conheci Freire via Pedagogia da Autonomia, a sua obra mais lida e citada, Pedagogia do Oprimido apresenta um pensamento potente por meio de uma linguagem

Rev. Nova Paideia - Revista Interdisciplinar em Educação e Pesquisa Brasília/DF, v. 3, n. 3. p. 36 - 48 - ANO 2021 
machista, que não retira a importância da obra, como pontuou bell hooks (2017). Apesar de Freire ter refletido sobre essas questões em Pedagogia da Esperança: Um reencontro com a Pedagogia do Oprimido (2021), publicada em 1992 e, na oportunidade, registrar as interpelações das feministas, é uma obra lida bem menos. Deveria ser uma leitura conjunta, pois são complementares e não só evidencia a potência de recriação da pedagogia do oprimido, como abre possibilidades para novas reflexões.

São pilares do pensamento freiriano, tanto a educação libertadora quanto a pedagogia problematizadora, sendo também suportes para uma nova sociedade, com relações de dominação suprimidas. Contudo, a pergunta "quem são os oprimidos hoje?" (COSTA et al, 2020) merece especial atenção, pois diz de todo ser que é desumanizado, que tem retirado de si a vocação de ser mais, que Paulo Freire defendeu (1996; 2011).

Pare e pense nesses sujeitos. Quem são para você? Para Leonardo Boff (2004, p. 9) no prefácio de Pedagogia da Esperança, oprimido "é o explorado econômico, é o condenado à ignorância, é o negro, o índio, o mestiço, a mulher, o portador de qualquer marca produtora de discriminação". Para mim são mulheres cis e trans, pessoas racializadas, LGBTs, imigrantes, refugiadas, pessoas com deficiências, da periferia do mundo. São pessoas da classe trabalhadora, afinal "a maior parte da classe trabalhadora global é constituída de imigrantes, pessoas racializadas, mulheres - tanto cis quanto trans - e pessoas de diferentes capacidades, cujas necessidades e os desejos são negados ou deturpados pelo capitalismo" (ARRUZZA et al, 2019, p. 55). São o contingente dos movimentos sociais, escolas e universidades públicas e com os quais precisamos dialogar.

A partir desta compreensão, entendemos porque qualquer sujeito oprimido rapidamente encontra abrigo na pedagogia do oprimido, tal como fizeram e ainda fazem muitas feministas e, espero ser ainda mais ampliado conforme a práxis feminista se difunde, pois trata-se de uma

(...). Pedagogia que faça da opressão e de suas causas objeto da reflexão dos oprimidos, de que resultará o seu engajamento necessário na luta por sua libertação, esta pedagogia se fará e refará

(...) A pedagogia do oprimido, que não pode ser elaborada pelos opressores, é um dos instrumentos para esta descoberta crítica - a dos oprimidos por si mesmos e a dos opressores pelos oprimidos, como manifestações da desumanização. (FREIRE, 2011, p. 43)

A linguagem machista não impediu que as feministas entendessem a mensagem escrita por Paulo Freira, pois identificaram as mulheres como oprimidas. Ao perceberem a necessidade de desenvolver uma pedagogia que promovesse reflexão sobre a opressão vivenciada pelas mulheres, igualmente impulsionou ações que reverberassem em melhoria de vida para elas. À pedagogia da oprimida, associaram uma educação como prática da Liberdade (FREIRE, 2011), ou seja, uma educação que negue a realidade sem as mulheres, de mulheres abstratas e idealizadas, desligadas do mundo. Em Pedagogia 
da Esperança, Freire faz uma autocrítica sobre a linguagem machista com a qual escreveu Pedagogia do oprimido:

De modo geral, comentando o livro, o que lhes parecia positivo nele a contribuição que ele trazia à sua luta, falavam, invariavelmente, do que consideravam em mim uma grande contradição. É que, diziam elas, com suas palavras, discutindo a opressão, a libertação, criticando, com justa indignação, as estruturas opressoras, eu usava, porém, uma linguagem machista, portanto discriminatória, em que não havia lugar para as mulheres. (...) E me perguntavam: "por que não, também, as mulheres?" (FREIRE, 2021, p. 92)

Ao reconhecer o machismo como um vírus do opressor, internalizado em si, Paulo Freire realiza um movimento genuíno da práxis da qual é porta-voz. bell hooks relata o quanto ser exemplo vivo do que defende é arrebatador, quando fala em Ensinando a transgredir: Educação como prática da Liberdade (2017) sobre seu encontro pessoalmente com Paulo Freire, na Universidade da Califórnia em Santa Cruz, Estados Unidos:

Enquanto lia Freire, em nenhum momento deixei de estar consciente não só do sexismo da linguagem como também do modo com que ele (e outros líderes políticos, intelectuais e pensadores críticos progressistas do Terceiro Mundo, como Fanon, Memmi etc.) constrói um paradigma falocêntrico da libertação - onde a liberdade e a experiência da masculinidade patriarcal estão ligadas como se fossem a mesma coisa. Isso é sempre motivo de angústia para mim, pois representa um ponto cego na visão de homens, que têm uma percepção profunda. (hooks, 2017, p. 69-70)

bell hooks segue alertando que tal ponto cego não deve ser motivo para descartar tais pensadores, principalmente quando são feministas que as leem, pois podemos aprender com suas percepções e, a partir da criticidade e de nossa percepção de mundo por meio das lentes de gênero, esse ponto cego pode ser visibilizado e, portanto, problematizado.

O sexismo de Freire é indicado pela linguagem de suas primeiras obras, apesar de tantas coisas continuarem libertadoras. Não é preciso pedir desculpas pelo sexismo. 0 próprio modelo de pedagogia crítica de Freire acolhe o questionamento crítico dessa falha na obra. Mas questionamento crítico não é o mesmo que rejeição."(hooks, 2017, p. 70).

À época que Paulo Freire escreveu Pedagogia do Oprimido (1968)e, mesmo antes em Educação como prática da Liberdade (1967), já haviam sido publicadas obras que são referências ainda hoje para o feminismo, como $O$ Segundo Sexo, de Simone de Beauvoir (1949), a tese de Heleieth Saffioti, intitulada A mulher na sociedade de classes: mito e realidade, defendida em 1968 e publicada como livro em 1969, para citar uma obra internacional e uma nacional. Além disso, como o próprio Paulo Freire afirmou, ele “já havia lindo um mundo de obras sérias" (FREIRE, 2021, p. 92). No entanto, creio que 
uma feminista freiriana não pode considerar um motivo de crítica tão dura, pois é o próprio pensamento freiriano que nos ensina sobre o inacabamento, o aprender permanente, que ninguém sabe tudo nem ignora tudo.

Assim, apesar do uso de mulher e homem após as críticas feministas, entendo que Freire não chegou a desenvolver reflexões efetivas em torno do gênero como tecnologia (LAURETIS, 1994), bem como presto demasiada atenção no quesito da linguagem, afinal é possível ter, como diz Freire (2021, p. 95) um "discurso democrático, antidiscriminatório" e uma "prática colonial"; é preciso engajamento em novos discursos democráticos e práticas democráticas, alega o mesmo autor.

A depender por qual obra inicie seu contato com o pensamento freiriano, as experiências vividas e os conhecimentos acerca de temas marginalizados e essenciais para a vida em sociedade, como gênero, raça e classe, as obras terão impactos diferenciados. Há quem, ainda hoje, se apoie no pensamento freiriano e, em um espaço com maior presença de mulheres, como a educação básica com as professoras, não perceba os desdobramentos ideológicos da invisibilidade das mulheres na carreira do magistério, por exemplo. Tal percepção, resultado de uma emersão do patriarcado como forma de hegemonia masculina, que se dissipa e se reproduz por meio de homens e mulheres, se expande para toda as esferas da vida social.

\section{Construindo uma pedagogia feminista}

Toda prática pedagógica se fundamenta em alguma teoria e em geral, teorias pedagógicas. Seja consciente ou não, este fundamento de ações está pautado em reflexões, que se feitas por sujeitos alheios à prática, deixa lacunas no processo educativo. Com a pedagogia feminista é semelhante e a adesão implica em estudos teóricos e mudanças metodológicas, como um processo de reeducação, afinal, não é possível ensinar o que não se sabe (FREIRE, 1996).

Algumas características constituem as propostas educativas classificadas como parte da pedagogia feminista, sendo a principal, considerar as desigualdades de gênero no diagnóstico e atos pedagógicos. Também, propor oposições ao modelo androcêntrico de educação, em que cooperação, subjetividade, aprendizagem e igualdade ocupam o lugar da competição, objetividade, ensino e hierarquia, presentes na educação formal tradicional. No entanto, ao invés desta dualidade, me parece mais adequado pensar tais características dialeticamente.

Ao tentar colocar no mesmo plano, com igual legitimidade, o saber pessoal e o saber acadêmico, as pedagogias feministas pretendem estimular a fala daquelas que tradicionalmente se veem condenadas ao silêncio, por não acreditarem que seus saberes possam ter alguma importância ou sentido. (LOURO, 2011, p. 117-118)

O que seria isso, senão o ensinamento freiriano de que não há saberes superiores ou inferiores, mas diferentes? Ao saírem do isolamento, as mulheres sobretudo em

Rev. Nova Paideia - Revista Interdisciplinar em Educação e Pesquisa Brasília/DF, v. 3, n. 3. p. 36 - 48 - ANO 2021 
grupos e por meio dessa educação e pedagogia feministas, permitem identificar as armadilhas da desigualdade de gênero, tal como a violência como estrutura social, da qual "A violência masculina contra a mulher nas relações pessoais é uma das expressões mais flagrantes do emprego abusivo da força para manutenção do controle e da dominação." (hooks, 2019, p. 179).

Essa conscientização advinda de uma educação como prática da Liberdade tem, na dialogicidade, o seu principal pilar. Diálogo é palavra, constituída de ação e reflexão, portanto de práxis; e a palavra verdadeira transforma o mundo (FREIRE, 2011). Portanto por meio do diálogo, as feministas difundem as ideias, contribuindo para que pessoas em geral, tendo como público principal as mulheres, percebam como as mulheres são oprimidas e precisamos deixar de ser, auxiliando na educação de outras.

A luta pelo reconhecimento enquanto ser humano, portanto a luta por humanização, atravessa toda a história das mulheres e o desenvolvimento do feminismo. Associada a esta defesa, o direito de ter acesso à educação formal, à escola, à Universidade, esteve como pauta permanente. As mulheres, consideradas objetos e não sujeitos, não aceitaram este lugar de passividade na história, promovendo uma verdadeira pedagogia da oprimida, uma pedagogia que ao emancipar as mulheres, emancipa todas as pessoas.

A mesma pesquisa que indica uma maioria de mulheres negras como trabalhadoras domésticas, fala sobre as mudanças provocadas pela elevação da escolaridade deste segmento de mulheres por meio do envelhecimento e de que as jovens com acesso à escolaridade e outras ocupações, migram para outros postos de trabalho, inclusive pelo estigma do trabalho doméstico. Contudo, estamos em período de crise para o capital e de reprodução social, o que significa que "O trabalho doméstico, em contextos de elevado desemprego e de precariedade do mercado de trabalho, sempre (re)aparece como uma alternativa para mulheres, especialmente aquelas com níveis mais baixos de escolaridade." (PINHEIRO et al, 2019, p. 13).

Assim, ao efetivamente trazer as mulheres no corpo dos seus escritos, de suas falas e de suas reflexões, Paulo Freire contribuiu com a propagação de ideias feministas que dizem sobre a visibilidade das mulheres, mas foram as próprias feministas que, se apropriando da noção da pedagogia do oprimido, construíram uma pedagogia da oprimida. Os três princípios centrais na pedagogia feminista sem dúvida nos lembram os princípios freirianos:

1 - resistência à hierarquia entre as e os educadores, de um lado, e as e os educandos, de outro, o que implica a participação das e dos últimos na construção de conhecimento e na definição do próprio processo de aprendizagem;

2 - tomada da experiência como recurso, para além dos métodos tradicionais, o que permite documentar e discutir experiências até aí 
alienadas, potenciadora da identificação de situações reais de opressão como base para a aprendizagem transformadora

3 - aprendizagem transformadora, que vai além da aquisição de novos conhecimentos para permitir pensar novos sentidos, incluindo a reinterpretação e revalidação crítica da experiência. (HENDERSON, 2016 apud MACEDO, 2021)

Enquanto uma pedagoga feminista que se orienta por tais princípios e características já listados, mantenho o diálogo como fio condutor do espaço educativo, seja em um trabalho com mulheres ou com mulheres, homens e pessoas não binárias. Isso pressupõe compreender que é preciso estimular que a palavra circule e que todas as pessoas presentes falem algo, nem que seja seu nome durante a apresentação, como ensina bell hooks (2017).

Para tanto, utilizo de metodologias feministas, que também possuem inspiração freiriana, como organizar o espaço em círculo ou, agora nestes tempos remotos, instigar a abertura das câmeras em sala de aula virtual. Uma rodada de apresentação e integração das pessoas participantes, seguida do conteúdo programático, preferencialmente oriundo daquele contexto, com mais problematizações do que exposições; por fim, espaço de avaliação e encaminhamentos posteriores. Deste modo,

a pedagogia feminista vai propor um conjunto de estratégias, procedimentos e disposições que devem romper com as relações hierárquicas presentes nas salas de aula tradicionais. A voz do/a professor/a, fonte da autoridade e transmissora única do conhecimento legítimo, é substituída por múltiplas vozes, ou melhor, é substituída pelo diálogo (...) (LOURO, 2011, p. 117)

O diálogo, de fato, possibilita construção coletiva por meio de reflexão também coletiva. Os grupos de reflexão feministas iniciados nos anos de 1970, durante o regime militar, no Brasil,

por incorporarem, sobretudo, mulheres ligadas, ou que se identificavam, de uma forma ou de outra, com o movimento popular, muitos desses grupos passaram a desenvolver um trabalho com grupos de mulheres dos setores populares e, nesse sentido, incorporaram às práticas dos grupos de autoconsciência feministas, metodologias e técnicas desenvolvidas pela Igreja, principalmente nas Comunidades Eclesiais de Base (CEBs), e outras organizações não-governamentais - o Movimento de Organização Comunitária (MOC), por exemplo - para o trabalho com os setores populares, todas elas inspiradas, em grande parte, na metodologia da "Pedagogia do Oprimido" de Paulo Freire. (SARDENBERG, 2011, p. 24)

O trabalho educativo que envolva mulheres, seja na escola ou nos movimentos sociais, implica em revisar e transformar as concepções e ações, em um verdadeiro movimento de práxis feminista, recolocando a educação política de mulheres no centro da agenda feminista. Ademais, para trabalhar com as lentes de gênero, raça, sexualidade, 
classe ou qualquer outra, requer um novo olhar, que não pode ser ensinado, "mas o resultado de um processo que se desenvolve aos poucos e em ritmos diferentes, a depender do indivíduo" (SARDENBERG, 2011, p. 22). Portanto, "As semelhanças entre o pensamento de Paulo Freire e a pedagogia feminista existe especialmente por meio da conscientização, diálogo, transformação social, valorização da experiência" (VIELMO, 2020, p. 318), características que integram as pedagogias críticas.

\section{Considerações finais}

Tanto a pedagogia freiriana quanto a pedagogia feminista são pedagogias críticas, portanto buscam refletir criticamente sobre a sociedade e transformá-la. Ao serem pedagogias abertas ao diálogo, torna-se possível que aprendam uma com a outra e o objetivo de transformação social se fortaleça. A esta altura está evidente tanto que a pedagogia feminista incorpora aspectos do pensamento de Paulo Freire, quanto que as feministas influenciaram a obra de Paulo Freire (VIELMO, 2020, p. 318).

Deste modo, o encontro entre pedagogia freiriana e pedagogia feminista fortalece suas bases na pedagogia do oprimido e da oprimida, na politicidade da educação, na dialogicidade, na problematização, conscientização e no sujeito coletivo. Trata-se de um encontro potente, cuja marca é o diálogo, o verbo em movimento. Ao ouvir e falar, mulheres e pessoas em geral elevam os níveis de reflexão e possibilidade de ação coletiva. A criticidade permanece ativa, negando dogmas e verdades absolutas, permitindo-se questionar a realidade com a intenção de transformá-la em um novo mundo, permeado pelos valores da solidariedade, igualdade e respeito.

Em 2021, no centenário de nascimento de Paulo Freire, mas antes mesmo, a chama do pensamento de Paulo Freire ficou mais intensa. Apesar de que há um espectro de ódio, mentiras e desonestidade em torno do legado de Paulo Freire, no Brasil, a partir da ascensão do bolsonarismo ao palácio central, nós, inclusive as feministas, precisamos lembrar de Paulo Freire como "um sujeito que amou profundamente o mundo, as pessoas, os bichos, as árvores, as águas, a vida"; ivaquele sujeito que provocava reflexõesações que promoveram mudanças, cujo legado segue vivo e nutrindo outras pedagogias, inclusive a pedagogia feminista.

\section{Referências}

ARRUZZA, Cinzia; BHATTACHARYA, Tithi; FRASER; Nancy. Feminismo para os 99\%: Um manifesto. Trad. Heci Regina Candiani. 1 ed. São Paulo: Boitempo, 2019.

BOFF, Leonardo. Prefácio. In: FREIRE, Paulo. Pedagogia da esperança: um reencontro com a pedagogia do oprimido.. 29a ed. São Paulo/ Rio de Janeiro: Paz e Terra, 2021, p. 09-12. 
COSTA, Ana Maria Morais; SANTOS, Simone Cabral Marinho dos; VALE, Elizabete Carlos do. 50 anos da Pedagogia do Oprimido: quem são os oprimidos hoje? Olhar de Professor, vol. 23, 2020. Disponível em: https://www.redalyc.org/journal/684/68464195063/ Acesso em 15 nov. 2021.

FEDERICI, Silvia. "Pandemia tornou mais dramático o que sempre existiu", diz filósofa Silvia Federici. José Eduardo Bernardes. Brasil de Fato, São Paulo (SP), 28 de Março de 2021b. Disponível em: <https://www.brasildefato.com.br/2021/03/28/pandemiatornou-mais-dramatico-o-que-sempre-existiu-diz-filosofa-silvia-federici > Acesso em: 03 abr .de 2021.

FREIRE, Paulo. Pedagogia da autonomia: saberes necessários à prática educativa. São Paulo: Paz e Terra, 1996.

FREIRE, Paulo. Pedagogia do oprimido. 50. ed. rev. e atual. Rio de Janeiro: Paz e Terra, 2011.

FREIRE, Paulo. Pedagogia da esperança: um reencontro com a pedagogia do oprimido. Prefácio de Leonardo Boff; notas de Ana Maria Araújo Freire. 29a ed. São Paulo/ Rio de Janeiro: Paz e Terra, 2021.

hooks, bell. Ensinando a transgredir: a educação como prática da liberdade [1994]. Tradução Marcelo Brandão Cipolla. São Paulo, SP: WMF Martins Fontes, 2017.

hooks, bell. Teoria feminista: da margem ao centro; tradução Rainer patriota. São Paulo: perspectiva, 2019.

LAURETIS, Tereza de. A tecnologia do gênero. In: HOLLANDA, H. B. de. Tendências e impasses. $O$ feminismo como crítica da cultura. Rio de Janeiro: Rocco, 1994.

LOURO, Guacira Lopes. Gênero, sexualidade e educação: uma perspectiva pósestruturalista. Petrópolis, RJ: Vozes, 2011.

MACEDO, Eunice. PEDAGOGIA FREIRIANA E PEDAGOGIAS FEMINISTAS: (DES)ENCONTROS E DIÁLOGOS (IM)POSSÍVEIS?. Ideação, [S. l.], v. 23, n. 1, p. 202 -, 2021. Disponível em: https://erevista.unioeste.br/index.php/ideacao/article/view/26306. Acesso em: 16 nov. 2021.

PINHEIRO, Luana; LIRA, Fernanda; REZENDE, Marcela; FONTOURA, Natália. Os desafios do passado no trabalho doméstico do século XXI: reflexões para o caso brasileiro a partir dos dados da PNAD contínua. Instituto de Pesquisa Econômica Aplicada. Texto para discussão. Brasília: Rio de Janeiro: Ipea, 2019.

SANTOS, Clea Gomes de Abreu dos; ALCÂNTARA, Janaina de Oliveira de. A graduação em pedagogia como base de ensino sobre relações de gênero a partir da concepção das discentes. Barreiras: UNEB, 2021. 55p. MONOGRAFIA (Graduação em 
Pedagogia): Universidade do Estado da Bahia, 2021. Disponível em: http://www.saberaberto.uneb.br/handle/20.500.11896/1765. Acesso em: 15 nov. 2021.

SARDENBERG, Cecília M.B. Considerações introdutórias às pedagogias feministas. In: COSTA, Ana Alice Alcantara; TEIXEIRA, Alexnaldo; VANIN, Iole Macedo (Orgs.). Ensino e Gênero: Perspectivas Transversais. Salvador: UFBA - NEIM, 2011, p. 17-32.

SCOTT, Joan. Gênero: uma categoria útil de análise histórica. Educação e Realidade. Porto Alegre, jul./dez. 1995, p. 71-9.

SILVA, Carmen. Os sentidos da ação educativa no feminismo. In: SILVA, Carmen (ogs.). Experiências em Pedagogia Feminista. Recife: SOS Corpo - Instituto Feminista para a Democracia, 2010, p. 8-27.

VIELMO, Paula. Pedagogia feminista e o legado de Paulo Freire: contribuições para uma educação como prática da Liberdade. Universidade e Sociedade, ano XXX, No 66, julho de 2020, p. 308-321. Disponível em: https://www.andes.org.br/sites/universidade e sociedade. Acesso em: 30 jul. 2020.

\footnotetext{
i Gravação disponível em: https://www.youtube.com/watch?v=1wG7AeyeKAI

ii bell hooks é o pseudônimo de Gloria Jean Watkins; é grafado em letras minúscula, como forma de que suas ideias sejam mais importantes do que seu nome, motivo pelo qual optei por mantê-lo nesta conformação ao longo do texto, suplantando as normas da ABNT.

iii Nós merecemos respeito! Caderno para professor, organizado por Ana Alice A. Costa, Alexnaldo Rodrigues, Iole Vanin e Suzana de Araújo (2005) e Ensino e Gênero. Perspectivas transversais, organizado por Ana Alice Alcantara Costa, Alexnaldo Teixeira Rodrigues e Iole Macedo Vanin (2011). Disponíveis para download em: http://www.neim.ufba.br/wp/publicacoes/.

iv Documentário "Paulo Freire Contemporâneo" (52 min), Disponível em: https://www.youtube.com/watch?v=WrUVnc7TPq8
} 